\title{
Neoliberalismo, antipoliticay crisis de la política en el Perú
}

\begin{abstract}
Antonio Romero Reyes
Universidad Ricardo Palma

Fecha de recepción 30-07-2018

Fecha de aceptación 03-10-2018

\section{RESUMEN}

El artículo busca comprender y desentrañar la naturaleza histórica de la antipolítica en relación con el neoliberalismo y el contexto de la crisis de la política que se vive en nuestro país. Se hace un recorrido por el marco histórico y teórico del tema, revisando textos de Degregori, Lynch y de otros autores latinoamericanos, centrando luego la atención en la crisis de los partidos y la economía política de la antipolítica. Las conclusiones son provisorias en el sentido de que se trata de respuestas tentativas a las siguientes cuestiones: ¿cómo acabar con la antipolítica?, ¿democratizando la democracia o refundando el país?
\end{abstract}

PalABRAS ClAVE: Neoliberalismo, antipolítica, Perú, América Latina.

\section{ABSTRACT}

The article seeks to understand and unravel the historical nature of anti-politics in relation to neoliberalism and the context of the crisis of politics in our country. A review is made of the historical and theoretical framework of the subject, revising texts by Degregori, Lynch and other Latin American authors, focusing on the party crisis and the political economy of anti-politics. The conclusions are tentative in the sense that these are tentative answers to the following questions: How to end antipolitics? Democratizing democracy or refunding the country?

KEYWORDS: Neoliberalism,Anti-politics, Peru, Latin America. 


\section{Introducción}

$\mathrm{E}$ objetivo del artículo consiste en comprender y desentrañar la naturaleza histórica de la antipolítica en relación con el neoliberalismo y el contexto de la crisis de la política que se vive en nuestro país.

La antipolítica fue uno de los pilares sobre los cuales se erigió el fujimorismo como régimen político en el Perú de los años $90^{1}$, comprendiendo por ende a los sucesivos periodos presidenciales del Ing. Alberto Kenya Fujimori Fujimori (19901992; 1992-1995 y 1995-2000), quien se halla cumpliendo condena de 25 años por delitos de lesa humanidad. En la actualidad, el fujimorismo es una corriente política organizada con el nombre de Fuerza Popular, siendo la principal fuerza de oposición en el Congreso.

En los 90 la antipolítica consistió en una práctica sistemática desde las esferas del poder persiguiendo conscientemente determinados resultados sobre la sociedad peruana, tales como el avasallamiento mediante el recurso al miedo y a la manipulación de la memoria colectiva, valiéndose de sutiles mecanismos ad hoc. En las mismas esferas del orden político y la gestión pública la antipolítica pasó a ser sinónimo de falta de ética, perversión de la política (siendo sus más nítidas expresiones el transfuguismo, el chantaje a los opositores, la corrupción de funcionarios y jueces), así como el envilecimiento de los valores y un estilo en general mafioso para "gobernar" (léase: hacer negocios oscuros). Como advirtiera Degregori, lo que emanaba del poder llegó incluso a ser asimilado por el comportamiento general, y en tal sentido enraizó en la sociedad.

La antipolítica en el Perú perduró más allá de los límites temporales que estaban implicados en el concepto. ${ }^{2}$ El fenómeno trascendió en el tiempo porque del inicial rechazo a la política de la época (años 90), calificada además de "tradicional" por el discurso, se la generalizó fácilmente para ser instalada como "rechazo a la política en general" (Degregori 2001: 36) en el inconsciente colectivo. Constituyó el contexto de referencia bajo el cual se educaron y formaron políticamente las nuevas generaciones.

1 "[...] el régimen fujimorista, surgido de la guerra victoriosa contra la subversión, la hiperinflación y los partidos tradicionales, logró esos triunfos a costa de construirse como régimen alrededor de la antipolítica, la personalización del poder y la defensa cerrada de la actuación del Estado en los años de violencia" (Degregori 2001: 14).

2 "Entre abril de 1992 y junio de 1995 se derrumbaron los grandes partidos peruanos del s. XX... Sin embargo, dijimos al principio que la antipolítica era efímera. ¿Cómo ha sobrevivido entonces tanto tiempo?" (Degregori 2001:21). 
La antipolítica en los 90 tuvo diversas manifestaciones: culto al liderazgo providencial encarnado en el entonces presidente Fujimori; denigración de la política hecha desde los partidos; autogolpe, cierre del Congreso y Constitución fujimorista de 1993; satanización y campaña de desprestigio contra opositores. Todas estas manifestaciones y algunas otras más acarrearon prácticamente la degeneración y trivialización de la política en el país.

La antipolítica se extendió como una plaga hacia otros escenarios de la actuación pública debido a la propia dinámica socio-histórica en el país, llevando a la desvalorización, el desapego y hasta la incredulidad sobre la democracia, la participación en política y el desprestigio de la institucionalidad existente.

En consecuencia, la antipolítica como proceso fáctico echó raíces desde los años 90 en el Perú, facilitado por un contexto de debilidad y crisis de la institucionalidad democrática, de la política en general y los partidos. Su persistencia en el tiempo ha dificultado la renovación de los liderazgos así como la aparición de una nueva generación de dirigentes políticos con visión de país. La comprensión del fenómeno y de su incidencia especialmente en la juventud tiene que ver con la necesidad de reemplazar el paradigma dominante que orienta la manera y los estilos de hacer política en el Perú. Más que un asunto del pasado reciente, la antipolítica es un tema de mucha importancia y actualidad en la explicación de los hechos y fenómenos políticos que vienen ocurriendo hoy en nuestro país.

El artículo hace un recorrido por el marco histórico y teórico del tema, centrando luego la atención en la crisis de los partidos y la economía política de la antipolítica, cerrando con las conclusiones.

\section{El proceso histórico de la antipolítica}

Como proceso político Degregori (2001: 25) ha distinguido la siguiente periodización: fujimorismo temprano (1990-1992), fujimorismo victorioso (1992-1996) y fujimorismo tardío (1996-2000). A continuación se explica sucintamente cada uno de estos periodos.

La llegada de Fujimori al poder del Estado (el primer periodo) fue facilitada y propiciada por la crisis de los grandes partidos y del sistema político en el país; crisis que se venía incubando desde los años $80^{3}$, aunque en 1990 todavía "era mucho

3 "En la década de 1980, en vez de ayudar a revertir la tendencia a la desarticulación [léase: de los partidos], los presidentes la acentuaron. Belaúnde reposó fuertemente en el apoyo a parientes y allegados personales. Alan García, a pesar de haber sido electo como candidato del APRA, el partido más antiguo y mejor orga- 
menos perceptible que la hiperinflación o el terrorismo, incluso para las propias dirigencias" (Degregori 2001: 32).

El pasaje del primer al segundo periodo está marcado por el autogolpe del 5 de abril del 92, apoyado masivamente por la población (entre 70 y $80 \%$ de aprobación), que significó la interrupción del régimen democrático como consecuencia de las tensiones que surgieron a propósito de los 15 decretos legislativos sobre pacificación, enviados por el Ejecutivo en noviembre de $1991 .{ }^{4}$

El fujimorismo victorioso tuvo un breve interregno como dictadura (abril a noviembre de 1992), que culminó formalmente con las elecciones para el Congreso Constituyente Democrático (CCD), debido a la presión de la OEA y del gobierno de los Estados Unidos, a fin de evitar el aislamiento internacional. Los principales hitos políticos de este segundo periodo fueron la captura de Abimael Guzmán alias "presidente Gonzalo" (12 de setiembre de 1992), la aprobación de la nueva Constitución mediante referéndum (31 de octubre de 1993), la reelección de Fujimori en abril de 1995 "con la más alta votación alcanzada por candidato alguno en el Perú desde 1950" (Degregori, 2001: 80), y la aprobación de la ley de “interpretación auténtica" (23 de agosto de 1996) con relación al artículo 112 de la Constitución del 93, la cual pasó a reemplazar a la del 79. De esta manera la dictadura se convirtió en un autoritarismo neoliberal reforzado además por la Constitución fujimorista.

Es en el periodo del fujimorismo victorioso donde se produce la debacle de los partidos, principalmente de Acción Popular (AP), del APRA y la Izquierda Unida (IU). ${ }^{5}$ Esta situación se halla en la base de la explicación de la entrada en escena de la antipolítica, como uno de los rasgos definitorios del fujimorismo, ${ }^{6}$ sustentado sobre una alianza de poderes fácticos:"servicios de inteligencia, Fuerzas Armadas, empresarios, medios de comunicación y tecnócratas vinculados a los organismos

nizado del país, gobernó prescindiendo de ella o sometiéndola a su voluntad personal, rodeado de amigos incondicionales. Ambos engrosaron las planillas burocráticas como forma de retribuir o asegurar lealtades clientelistas." (Degregori, 2001: 39).

4 "Entre agosto de 1990 y marzo de 1992, movidos por el desconcierto y el instinto de supervivencia, los partidos ensayaron cambios y adoptaron una actitud de cooperación con el nuevo gobierno.[...] Durante esos 20 meses, incluso luego del desmantelamiento del gabinete plural, el Congreso de mayoría opositora delegó quince veces poderes legislativos al Ejecutivo" (Degregori, 2001: 32). El fondo de la disputa en torno a los decretos sobre pacificación era la modificación de la estrategia antisubversiva.

5 "Entre abril de 1992 y junio de 1995 se derrumbaron los grandes partidos peruanos del s. XX, que expresaron y en cierta medida canalizaron la irrupción sucesiva de grandes bloques demográficos en la vida política del país, y les proporcionaron identidad y representación" (Degregori, 2001: 21).

6 "El éxito, y sobre todo la larga duración de la antipolítica en el Perú, tuvo que ver directamente con el colapso de los partidos" (Degregori, 2001: 35). Más adelante el mismo autor sostiene: "La muerte de los grandes partidos sin poder reformarse, y la imposibilidad de construir otras representaciones políticas adaptadas a los nuevos tiempos ha sido uno de los hechos más nefastos de la década, pues permitió el imperio de la antipolítica más allá de cualquier pronóstico" (ídem, 36-37). 
financieros internacionales" (Degregori 2001: 62). Con base en esta alianza el Ingeniero Fujimori, "el antipolítico más radical y más exitoso de la región" (ídem, 34-35), logró derrotar electoralmente y/o someter a sus principales rivales políticos de entonces como Javier Pérez de Cuéllar, Ricardo Belmont y Alberto Andrade, en una década donde se vivió “la apoteosis de los independientes" (Degregori 2001: 62).

Por último, el tercer periodo, es el del desmoronamiento del régimen que en lugar de una mayor apertura se caracterizó por acentuar sus rasgos autoritarios. Se inició con los primeros intentos de oposición organizada (campaña de firmas contra la "segunda reelección" del 2000; movilizaciones de rechazo contra la destitución de los integrantes del Tribunal de Garantías Constitucionales); ; las revelaciones propaladas por un canal de televisión que involucraban al Servicio de Inteligencia Nacional (SIN) en torturas o asesinatos de sus agentes (casos de Leonor la Rosa y Mariela Barreto, respectivamente), así como en chuponeos e interceptaciones telefónicas; las afirmaciones que provocaron escándalo público provenientes del narcotraficante Demetrio Chávez Peñaherrera, conocido como "Vaticano", sobre sus conexiones con Vladimiro Montesinos y los pagos que este recibía de aquel. De esta manera fue como el doctor Montesinos — como se hacía llamar - saltó abruptamente a la luz pública, proyectando una sombra de dudas y sospechas sobre el gobierno al cual servía. ${ }^{8}$

\section{La antipolítica en Bolivia, Ecuador y Perú}

La antipolítica es un término escasamente utilizado por las ciencias sociales latinoamericanas, siendo aun prácticamente desconocido por las ciencias sociales en general y por la ciencia política en particular: el término está ausente, por ejemplo, en la Enciclopedia de la Política de Rodrigo Borja (2003), expresidente del Ecuador (1988-1992). El uso del término ha buscado dar cuenta de fenómenos o procesos políticos específicos, localizados especialmente en los países andinos. René Mayorga habría sido el primero en acuñarlo y utilizarlo para el contexto boliviano, asociándolo con el neopopulismo latinoamericano y el fenómeno katarista en Bolivia. ${ }^{9}$ Ubica

7 Sobre el TGC véase la nota 22, infra.

8 Las confesiones del Vaticano se produjeron en el marco de un juicio público, el 16 de agosto de 1996. Refiriéndose a Vladimiro Montesinos, involucrado por Vaticano, Degregori concluye: “El topo siniestro había quedado irreversiblemente expuesto y de la peor manera. También salió a la luz su descomunal poder" (2001: 83). Y más adelante: "El pasivo político más neto pero al mismo tiempo inevitable del segundo fujimorismo fue Vladimiro Montensinos" (ídem, 91).

9 En el prólogo a su libro La antipolítica en expansión Mayorga (1995: 11) deja establecido el alcance global del fenómeno que se propone estudiar. El autor se apoya en el seminario "The Politics of Antipolitics" organizado 
a la antipolítica como "una tendencia sin precedentes" (Mayorga 1995: 7) a nivel latinoamericano, que se puso de manifiesto desde inicios de la década de los 80, a través de la detección de las brechas de confianza entre ciudadanía y partidos políticos, de un lado, y entre ciudadanía y Estado, del otro.

Corroborando la aparición del fenómeno, en el caso peruano el discurso y la práctica de la antipolítica surgieron durante la "década larga" (Lynch 2000: 15) que va del 28 de julio de 1980 (fecha del primer discurso del presidente Belaunde al inaugurar su segundo gobierno) al 5 de abril de 1992 (día del autogolpe del hasta entonces presidente Fujimori declarando "disolver" el Congreso). La antipolítica en el Perú fue fruto del fracaso histórico de la política entendida en una doble dimensión: la política como democracia (o gestión democrática) hecha por las élites; y la política como despliegue de guerra en términos de subversión o de guerra sucia (Lynch 2000: 15-23). Fue una variante de la segunda (la política como guerra sucia) la que "desbrozó el camino para el advenimiento de la antipolítica" (loc. cit.: 22).

El otro país andino donde, como en Bolivia, la antipolítica fue asociada con el neopopulismo, es Ecuador que junto con Brasil, Argentina y la misma Bolivia es uno de los países sudamericanos con una larga tradición política populista. A comienzos de siglo un politólogo ecuatoriano (Echeverría 2006) se preguntaba si neopopulismo y antipolítica son dos formas políticas distintas o dos aspectos de la misma forma de hacer política. Echeverría sostiene - y esta fue la novedad en el caso ecuatoriano - que el registro discursivo de la antipolítica (promovida por el hoy ex presidente Rafael Correa y su organización Alianza País) contribuyó a generar las condiciones para el surgimiento del neopopulismo, representado por dos fuerzas: la del empresario Álvaro Novoa y su Partido Renovador Institucional Alianza Nacional (PRIAN); y la del coronel expresidente Lucio Gutiérrez con el Partido Sociedad Patriótica (PSP), en el contexto de las elecciones presidenciales del 2006. En medio de la crisis política que se vivió en Ecuador desde la destitución del presidente Abdalá Bucaram (agosto 1996 a febrero 1997), antipolítica y neopopulismo comparten para Echeverría la misma lógica corrosiva del sistema de representación que era caricaturizado despectivamente como "partidocracia", desprestigiando de esta manera y paradójicamente a la política en el Ecuador. ${ }^{10}$

por el Vienna Dialogue on Democracy (Viena, 7 a 10 de julio de 1994), evento que representó el primer reconocimiento internacional del tema. Sin embargo, al final del mismo prólogo reconoce que es un tema nuevo que "merece ser objeto de investigación sostenida" (1995: 22).

10 En un libro más reciente (Echeverría, 2015: 89) identifica la antipolítica (o el "fenómeno antipolítico") en términos del "rechazo o enfrentamiento a la lógica de la representación." En el caso ecuatoriano este rechazo no vino promovido desde arriba — como en el Perú — sino que fue generado desde los movimientos sociales. 
La corrupción de los políticos ha sido para el politólogo boliviano René Mayorga "el fermento inmediato de la antipolítica" (1995: 10). Para este autor el Perú e Italia eran los "dos casos extremos y 'paradigmáticos' de irrupción exitosa de la antipolítica" en los años 90 (1995: 14). En el contexto de su trabajo la antipolítica viene a ser el "poder de los outsiders y movimientos antipolíticos" (en el caso peruano, constituido por el Ing. Alberto Fujimori y el movimiento de seguidores que fundó, identificado como fujimorismo).

Según el contexto de cada país, la antipolítica en el doble sentido de rechazo a los partidos establecidos y como demanda social (en el Perú como demanda de pragmatismo, en el caso ecuatoriano como demanda de derechos) se encontró y complementó con el neoliberalismo que preconizaba la separación entre economía y política. Esta separación traducía en términos académicos el rechazo visceral, en términos políticos, de toda intervención o intromisión del Estado en el manejo de los asuntos económicos. La antipolítica, en cambio, implicaba el desahucio del tema del poder (y las relaciones de poder) como objeto (campo) de interés de la política. En lugar de la política entendida como competencia democrática, conflicto de intereses sociales (o de clase), lucha por el poder, antagonismo, confrontación de ideales y de propuestas programáticas, lo que se instaló en la opinión y el imaginario colectivo fue el discurso tecnocrático de una nueva manera de hacer política, que pasa a ser sinónimo de tolerancia, diálogo, consenso y armonía social. Si reconocemos la doble dimensión de la política:"de conducción de seres humanos y de administración de cosas" (Borja 2003: 1106), es fácil darse cuenta dónde recaía ahora el énfasis. En realidad, el propósito buscado era la "desaparición casi absoluta del componente político de la propia política" (Fair 2012: 6); y este componente político es el poder por antonomasia. ${ }^{11}$

Queda claro que a la antipolítica se la puede comprender (es decir, cómo o de dónde se origina) por el contexto histórico donde surge (v. gr. la crisis de los parti-

11 "La política es fundamentalmente poder" (Borja, 2003: 1106). Touraine explica muy bien cómo se genera, discurre y en qué remata el proceso de separación: "El pensamiento liberal se basa en la desconfianza con respecto a los valores y a las formas de autoridad que los hacen respetar. Separa el orden de la razón impersonal, que debe ser el de la vida pública y que es también el de la utilidad, y el orden de las creencias, que debe seguir siendo del de la vida privada. No cree en la existencia de actores sociales definidos a la vez por unos valores y unas relaciones sociales. Cree en los intereses y en las preferencias privadas y procura dejarles el mayor espacio posible, sin atentar contra los intereses y las preferencias de los demás. [...] Pero, para que esta conciliación de los fines sea posible, es preciso que cada uno de éstos renuncie a su pretensión a lo absoluto, es decir que deje de ser una creencia y se limite a ser, ya un interés, ya un gusto o una opinión que no podrían pretender imponerse a los otros. Lo que implica una imagen de la vida social de la que son excluidos a la vez las creencias y los conflictos sociales fundamentales y, por consiguiente, la idea misma de poder. La sociedad ideal es concebida como un mercado, lo que por otra parte no excluye la intervención de la ley y el Estado, pero para hacer respetar las reglas del juego, la honestidad de las transacciones y la libertad de expresión y acción de cada uno." (Touraine, 1998: 70-71). 
dos y/o del sistema político), por asociación con otros fenómenos sociopolíticos (el neopopulismo) o simplemente como algo derivado por una relación de oposición (lo opuesto a la política) en un contexto hermenéutico.

El neoliberalismo propende a la despolitización y la desideologización de los individuos y la sociedad, lo cual alimenta y es caldo de cultivo para el surgimiento de la antipolítica. Asimismo, podemos razonablemente suponer que existen vínculos estrechos de la antipolítica con categorías como la democracia y el populismo. ${ }^{12}$

Lo esencial a saber es que la antipolítica no solamente comporta determinadas actitudes frente a la política: es también y sobre todo una forma de hacer política. Más aún, implica prácticas perversas que conducen indefectible e inevitablemente a la degeneración de la política. En este sentido, todos aquellos factores sociales, políticos, ideológicos o culturales que menguan o menoscaban a la política (p. ej. la corrupción en las altas esferas del Estado), se retroalimentan con laantipolítica y, a la larga, afectan a toda la polis (la sociedad política; el sistema de partidos; la institucionalidad), por ende, a la mismísima democracia. ${ }^{13}$

\section{Crisis de los partidos y la antipolítica en el Perú}

Si el periodo 1980-1992 (hasta el momento del autogolpe del 5 de abril) representó el de la derrota de los partidos populistas (Lynch 1999), la década de los 90 fue el periodo de la antipolítica (Degregori, 2001) y al mismo tiempo — como ya se vio anteriormente- la década del "derrumbe" de todos "los grandes partidos peruanos del s. XX" (Degregori 2001: 21). Tanaka (1998) sostiene en cambio, para el lapso de tiempo 1980-1995, la tesis del "colapso del sistema de partidos", no solo de los partidos políticos en sí mismos, populistas o no; y a este colapso le siguió —-según él mismo — una "democracia sin partidos" (Tanaka 2005). ${ }^{14}$ Julio Cotler, empleando

12 Debido a limitaciones de espacio se deja para otra oportunidad la demostración de los vínculos conceptuales de la antipolítica con otras categorías de las ciencias sociales.

13 Borja dice del populismo que:"En cierto sentido es la antidemocracia"(2003: 1110). De su parte, Touraine argumenta con mucha autoridad: " ¿Qué ocurre cuando los actores políticos no están sometidos a las demandas de los actores sociales y pierden por lo tanto su representatividad? Así desequilibrados, pueden inclinarse hacia el lado del Estado y destruir la primera condición de existencia de la democracia, la limitación de su poder. Pero, si esta situación no se produce, la sociedad política puede liberarse a la vez de sus lazos con la sociedad civil y el Estado y no tener ya otro fin que el crecimiento de su propio poder." (Touraine, 1998: 85). Esta situación para Touraine conduce a la partidocracia y a la corrupción de determinados dirigentes, ejerciten o no cargos públicos. Podemos asociar la partidocracia con las brechas de confianza mencionadas por Mayorga (1995) como una de las fuentes de la antipolítica.

14 El título (así como el contenido) del libro de Tanaka está posiblemente inspirado en el artículo de Levitsky \& Cameron (2003). 
otras categorías conceptuales desde la sociología política, ha preferido caracterizar los años ochenta de "crisis de gobernabilidad" (Cotler 2000: 17-22) y a la del noventa la ha denominado "década del autoritarismo". Por último, Grompone (2005) constata la persistencia de la debilidad de los partidos a comienzos del siglo XXI, como uno de los "legados" que dejó el fujimorismo, situación agravada por la manera como se condujo el gobierno de Alejandro Toledo.

Dichas caracterizaciones tendrían una plataforma común que se puede identificar en términos de desencuentros, desfases, procesos de separación, grietas u otros similares: entre sociedad y política, entre ciudadanía y Estado, entre economía y política, entre sociedad civil y sociedad política; en última instancia, remiten a la figura del triángulo sin base consagrada por Cotler (1969: 65), o al más elaborado concepto de dependencia estructural de Quijano (1977:246-247). ${ }^{15}$ Lynch, por ejemplo, sostuvo que las formas de representación populista y corporativa cumplieron un rol de integración solamente de algunos segmentos sociales cuyos derechos les fueron gradualmente reconocidos ( $p$. ej. los migrantes con sus demandas de servicios y condiciones de habitabilidad urbana). Sin embargo, "una vez cumplido este papel de integración parcial, estas formas de representación no fueron capaces de expresar a los nuevos sectores sociales que surgieron de la década de 1970 en adelante. Se produce entonces el desfase entre la sociedad civil y la sociedad política" (Lynch 2000: 17).

Desde los albores de la República han coexistido conflictivamente en el país dos sociedades: una (la de las mayorías) que pugna por ser reconocida y otra (la de las elites en el poder) que bloquea y hasta reprime a la primera. ${ }^{16}$

En los tiempos más recientes, y en el marco del Estado peruano actual, la sociedad que es hilvanada desde las mayorías busca instalarse en base a principios de derechos, inclusión, equidad en las relaciones de género, solidaridad económica y social, sustentabilidad ambiental, pluralidad y diversidad étnica, justicia distributiva. En cambio, la sociedad que ya ha sido construida y se quiere mantener tal cual por las elites con sus propias reglas, es aquella que niega o pretende supeditar / someter dichos derechos a los consensos del poder económico basados en "las leyes infalibles del mercado": propiedad privada, inversiones y crecimiento econó-

15 Posteriormente, a fines de los 80 el concepto de dependencia estructural daría paso al de heterogeneidad estructural en el pensamiento de Quijano.

16 Por"mayorías" en el Perú de hoy se entiende un abanico heterogéneo de grupos, sectores, capas, segmentos etáreos y estratos sociales: trabajadores del campo y la ciudad, obreros, artesanos, microempresarios, hombres y mujeres, desempleados, auto empleados, cesantes y jubilados, maestros, jóvenes de ambos sexos, pobladores urbanos, campesinos pobres y pequeños productores, estudiantes universitarios, infancia, adultos mayores, los pueblos indígenas, amazónicos y afroperuanos. Seguramente la lista es mucho más larga de lo que pretende esta señalación. Con todo, se trata de la mayoría del Perú. 
mico, principalmente. Es en esta pugna permanente y vuelta insoluble a pesar de los tímidos intentos de concertación, donde siempre se ha insertado y actuado el sistema de partidos en el Perú, sin haberse podido transformar en un sentido plenamente democrático. La tradición democrática en el Perú ha estado mayormente en correspondencia con una democracia delegativa, en el sentido de O'Donnell (1994: 12-15), es decir, un híbrido entre el regreso persistente al autoritarismo de las elites civiles y militares, y un régimen democrático "institucionalizado y consolidado" que hasta el momento, en el Perú, parece inalcanzable. ${ }^{17}$

Con respecto a los aspectos estáticos que según O'Donnell caracterizan a la democracia delegativa, destacan los que más se emparentan con el populismo $y$, a través de este, con la antipolítica. Se trata de aquellos aspectos en que: 1) el líder político democráticamente elegido y ungido presidente, se erige / es erigido al mismo tiempo como "el principal intérprete" o "la encarnación" de los intereses nacionales. 2) A esta auto-concepción del elegido —no exenta de rasgos teleológicos ni mesiánicos - se endosa además una "misión" (o varias misiones) que cumplir, lo que se traduce en una serie de decisiones y "prácticas de poder" que no necesariamente pasan por (más bien pasan por encima de) las instituciones establecidas llegando hasta el aborrecimiento de las "interferencias" (léase: control, fiscalización, rendición de cuentas) sobre el poder ejecutivo.

La crisis de los partidos y del sistema de partidos, en realidad, se halla inserta en una cuestión mayor y más compleja: la larga duración del fallido Estado peruano y sus elites. Efectivamente, a lo largo de 20 años (décadas del 80 y 90 ) nuestro país reunía varias de las características que permitían identificar un Estado fallido (Alcalde 2004: 223-256): violencia política, prácticas terroristas por parte de Sendero Luminoso y del mismo Estado contra poblaciones andino-rurales alejadas e indefensas, elevada corrupción en el sector público, deterioro del nivel y calidad de vida. De este listado de problemas el que persiste hasta hoy es la corrupción desplazando incluso a otros temas importantes de la agenda pública como la pérdida de recursos naturales, el cambio de modelo económico, la nueva estrategia de desarrollo del país, las reformas del Estado, la reforma del sistema de partidos políticos. La corrupción corroe a todas las instancias estatales sin excepción, en términos sectoriales, regionales y aun de nivel local, habiendo sido testigos en los últimos años de situaciones que han merecido el generalizado rechazo y desaprobación de la ciudadanía.

17 En un texto más reciente el mismo autor (O'Donnell 2010) reconoce como democracias delegativas en el Perú a los dos gobiernos de García Pérez y al de Fujimori en su primer periodo antes del autogolpe (1990-1992). 


\section{Economía política de la antipolítica}

La antipolítica es la consecuencia de la derrota de las luchas sociales y populares en los 80 , comprendiendo incluso a las de carácter "clasista", que demandaban cambios y/o reformas que favorecieran sus condiciones materiales de existencia (mejoras salariales, reducción de la carestía, empleo, vivienda, suelo urbano y otros), manifestándose estas demandas en términos electorales a favor de fuerzas políticas de izquierda o de centro. El caos y desorden a los que condujo la gestión gubernamental del primer gobierno de Alan García llevaron a que las demandas sociales se transmutaran en "la búsqueda de orden", facilitando de esta manera el ingreso de la antipolítica (Lynch 2000: 23). ${ }^{18}$

La antipolítica en el Perú de los 90 presentó los siguientes rasgos:

1. Un tipo de liderazgo independiente, incontaminado, "salvador" y de carácter plebiscitario (apelación del líder a la población). Este tipo de liderazgo recibió el apelativo de outsider pues apareció por fuera de los partidos y del sistema político. Los primeros outsiders en el país pero más orgánicos — según Lynch (2000: 23-24) — fueron Alfonso Barrantes, líder de la Izquierda Unida (IU), y Mario Vargas Llosa, líder del Frente Democrático (Fredemo), coaliciones de partidos de izquierda y derecha respectivamente. A ellos se sumaron Ricardo Belmont, Alberto Fujimori y outsiders en las provincias donde ocuparon cargos en las municipalidades. ${ }^{19}$

2. Una relación personal y clientelista que desarrolla el caudillo con la masa indiferenciada, por encima de cualquier mediación partidaria, lo que genera la identificación con aquel (una "representación simbólica", dice Lynch, tomada a su vez de Hanna Pitkin) porque supuestamente les atiende sus problemas concretos y crea así la consiguiente "ilusión de participación" en el poder.

3. Un discurso sobre el manejo de los asuntos públicos que es concedido a los independientes, técnicos e individuos calificados, sean civiles o militares, poniendo en contrapartida un "discurso negador de la política": la supuesta incapacidad de los políticos para adoptar decisiones "técnicas".

La combinación de los dos últimos puntos dio lugar a lo que Lynch (2000: 26) denominó una legitimidad por resultados de la antipolítica, que se complementa con

18 Sobre el primer periodo de gobierno de Alan García Pérez ver Crabtree (2005).

19 Belmont fue "el primer independiente que puede considerarse outsider" $\mathrm{y}$ "el primer líder abiertamente antipolítico del periodo" (Lynch, 1999: 212 y 213). Sobre el tema de los independientes y los outsiders en el Perú ver Lynch (1999: 59-69; 208-230). 
la institucionalización del régimen mediante una legitimidad legal (la Constitución propia y la reforma del aparato estatal).

Pero la antipolítica, además de la arena política, ha tenido sus prolongaciones en otras áreas de la gestión estatal, particularmente en la economía. Así, las orientaciones estratégicas para la gestión de la economía son cedidas a $-\mathrm{y}$ comandadas por - una elite tecnocrática que prioriza los intereses e inversiones de las grandes corporaciones, que son encubiertos con el discurso ideológico y estadístico de los mercados. De esta manera, la realpolitk en el Perú consiste en que la economía a secas (léase: las fuerzas de la globalización y sus aliados internos) es la que conduce efectivamente a la política y al país todo comprendiendo a incluidos y excluidos.

El argumento anterior se puede ilustrar a nivel micro, para lo cual se recurre a la opinión del sociólogo portugués De Sousa Santos:

Cuando el Estado privatiza el agua la compañía privada que va a controlar el agua tiene un poder político sobre los ciudadanos, el poder de la sobrevivencia de los ciudadanos, y esto es un asunto político, pero la compañía no es política sino económica. Entonces tenemos aquí un gobierno indirecto en que grupos económicos ejercen poder político en nombre del Estado. El Estado dice que los regula, pero es rehén de esos intereses y por eso, a la vez que regula, es regulado por ellos (De Sousa Santos 2003: 6-7).

Ese control político que ejerce la empresa privada del agua, o el "gobierno indirecto", también se da con los casos de la energía eléctrica, telefonía y otros servicios privatizados. Se prolonga asimismo con la banca privada, los seguros y los fondos de pensiones que manejan las AFP. A este dominio se añaden las presiones de los lobistas para incorporar la educación y salud. En el fondo de todo esto se trata de la misma racionalidad: el control de las condiciones de existencia de los ciudadanos, que son conducidos y maniatados por la lógica de la ganancia y del capital. Los ciudadanos son convertidos en seres "deseantes".20

La antipolítica, entonces, en el campo de la economía coincide con los mismos propósitos políticos del discurso neoliberal, que denigra de la eficacia del Estado y lo aparta de toda intromisión o intervención que perturbe el funcionamiento ar-

20 "Enajenar la voluntad es proponer la pérdida de centralidad del sujeto y de lo político. La voluntad del sujeto se transfiere al sistema. El individuo se despoja [es despojado] de su voluntad y se reduce a un ser deseante en el interior de un sistema ya construido donde los catalizadores son las vías de comunicación propuestas desde el sistema para el manejo de los operadores sistémicos." (Roitman, 2004: 110). 
monioso de la"mano invisible".2. La participación del Estado es reducida al mínimo necesario. De ahí proviene la metáfora del "piloto automático"cuando toda la charlatanería economicista (y por ende, antipolítica) se traduce en el manejo "técnico" de los asuntos económicos. Constituye un formato común que viene dándose en el Perú desde los años del fujimorato, siendo compartido por todos los gobiernos que le han sucedido (incluyendo el gobierno "nacionalista" de Ollanta Humala) desde que se privatizaron a mansalva las empresas públicas.

La conjugación de la antipolítica con el neoliberalismo ha producido un novedoso tótem: el totalitarismo del mercado, el moderno fetiche invocado por los edulcorados para exorcizar cualquier amenaza (interna o externa); fetiche $y$ fetichismo que esconde la realidad del capitalismo de las transnacionales y sus estrategias de expansión/dominio sobre los territorios, recursos y productos del trabajo y la naturaleza del país.

El crecimiento económico que experimentó el Perú, y al que tanto se le rinde culto por parte de políticos, grandes empresarios y periodistas, vino acompañado por el descrédito de la política, los partidos políticos y la institucionalidad democrática en general. Lo que Jaime de Althaus denominó con mucho entusiasmo la "revolución capitalista en el Perú" (2007), encierra un fenómeno más complejo que va más allá de la existencia de una "democracia sin partidos" (Tanaka 2005), o del empobrecimiento de la política peruana (César Hildebrandt): se trata de la muerte de la vieja política en un país como el Perú. Esta es la tendencia inversa, aparentemente irreversible y contradictoria que ha acompañado, en contrapartida, al famoso crecimiento económico.

Lo grave es que el desfallecimiento de esa política, en las condiciones actuales del Perú, está dejando un agujero negro que nadie, ningún actor colectivo, ningún "salvador providencial", ninguna institución por muy democrática y confiable que fuese, es ni será capaz de llenar por sí mismo. A esto nos está conduciendo políticamente el camino por el que persiste en llevarnos la vieja política. Políticos como Alan García y todos quienes piensan como él, creen que el Perú seguirá siendo habitado por borregos y débiles mentales, subhumanos y "perros del hortelano", un pueblo

21 El neoliberalismo surgió en el siglo xx, primero como una ideología académica, durante el periodo conocido como "guerra fría", a la sombra de la revolución keynesiana, en universidades de Europa occidental y EEUU. Apareció principalmente desde los ámbitos de la filosofía política y la economía, siendo en esta última donde se revistió de un elevado grado de formalización. En realidad, cualquiera sea su fuente, el neoliberalismo viene a ser un refrito del pensamiento liberal del siglo XIX, especialmente del último tercio. Sus postulados, supuestos y premisas, presentados tramposamente bajo el membrete de "economía científica", han dado lugar - en el terreno de la política- a concepcionesa-históricas sobre la libertad y la democracia, contaminadas además de economicismo, pues ambas son entendidas como entes "puros y perfectos", es decir, una verdadera utopía arcaica y, además, colonialista. Para una discusión más amplia cf. Romero (2012). 
peruano siempre necesitado de "salvadores" y caudillos. Esto representa justamente la vieja política que se resiste a morir, ... pero está muriéndose, quiérase o no. Muchos han identificado la vieja política con el desprestigio de la institución parlamentaria: de ninguna manera la argumentación desarrollada en este trabajo se reduce solo a eso.

\section{Conclusiones}

Se extraen algunas conclusiones provisorias y tratando responder a las siguientes inquietudes: ¿cómo acabar con la antipolítica?, ¿democratizando la democracia o refundando el país?

Pareciera que para superar la antipolítica es necesario emprender una tarea titánica que las actuales generaciones de políticos, aquellos que ocupan actualmente la escena oficial, difícilmente estarían en condiciones de asumir: el reto de romper definitivamente con la herencia colonial; el dejar de ser un Estado nación fallido; un país con democracias realmente existentes (es decir, delegativas); un país donde la anomia es la regla antes que la excepción; donde el crecimiento económico es el nuevo opio del pueblo; donde, si bien el país ha experimentado procesos de incorporación e inclusión, aún persiste — como diría O’Donnell—“una ciudadanía socialmente fragmentada y políticamente alienada" (2010: 4).

Las alternativas entre democratizar la democracia o refundar el Perú no deberían verse como necesariamente excluyentes, ya que la primera puede considerarse como el paso (o un requisito político) previo para el tránsito a la segunda. Otro punto de vista podría considerar que la primera tarea es la refundación (del Estado y de la política), sin la cual es difícil — por no decir imposible—democratizar todas las instituciones y todos los espacios de decisión donde se dirimen los asuntos colectivos, es decir, para poder emprender procesos de democratización; y la refundación puede implicar una revolución social como opción abierta, revolución proveniente desde las profundidades de la sociedad (desde abajo hacia arriba, no al revés). ¿Existirán alguna vez las condiciones sobre todo subjetivas para este tipo de opción en el Perú, en algún momento del siglo XXI? Tanto esta pregunta como la misma alternativa de la refundación presuponen la existencia de la antipolítica, así como una situación política agravada. Hemos llegado a plantear una cuestión difícil y complicada de responder en el marco del presente trabajo, con relación a la cual solo se adelantan algunos atisbos.

Si la clave del futuro es lo que hagamos en el tiempo presente, cabe cuestionar: ¿Seguimos conviviendo con la antipolítica que existía en la década de los 90 en el 
Perú? Esta pregunta tiene dos respuestas básicas. Una es al nivel de las correlaciones de fuerzas en el Estado peruano, donde fundamentalmente el régimen autoritario y mafioso de Fujimori-Montesinos se desmoronó a fines del 2000 gracias a la filtración pública del famoso video Kouri-Montesinos y a la reacción social que generó despertando del letargo, ${ }^{22}$ a cuya cabeza se puso un recién llegado a la política oficial (Alejandro Toledo) con el apoyo de una coalición de fuerzas antidictadura (agrupadas en el Foro Democrático). Sin embargo, la "democracia sin partidos" se ha prolongado y ha perdurado más allá del $2000 .{ }^{23}$ Su mantención en el tiempo, sin reformas en el sistema político que resuelvan en serio la debilidad de los partidos, constituye también una ventana abierta a la antipolítica.

La otra respuesta es a nivel de la sociedad, la ciudadanía y especialmente de los sectores populares. La antipolítica es en realidad prima hermana de la vieja política. Esta última consiste en el vergonzoso espectáculo al que nos han acostumbrado las elites: el de las componendas y los arreglos por debajo de la mesa; la falta de transparencia y el ocultamiento de información; el oportunismo político y los cambios de camiseta; la falta de principios, la incoherencia entre el discurso de las promesas y las políticas de gobierno; actos reñidos con la ética, etc. Los sectores populares, divididos como están, desorganizados y dispersos, fragmentados y políticamente desorientados, tardarán un tiempo — corto o largo, difícil saberlo- en comprender que ellos son los depositarios de las mejores expectativas de que desde su interior puede surgir el sepulturero que acabe con ese estado de cosas que lleva a la mediocridad, la corrupción, el transfuguismo y tantas otras lacras de la vieja política.

La "refundación" del país como un proceso social y político de largo aliento provendrá sobre todo de allí (el Perú refundándose desde su propia conformación social, étnica y de clases), no tanto por las acciones de un "buen gobierno" nacionalista, de izquierda, centro o"progresista". Sería el verdadero tributo desde lo más profundo del Perú a los ideales de nación de José María Arguedas y a los anhelos socialistas de José Carlos Mariátegui.

22 El malestar social se había manifestado en años previos (1997-1998) con relación a la destitución de tres magistrados del Tribunal de Garantías Constitucionales que habían votado por la "inaplicabilidad" de la Ley $N^{\circ} 26.657$ promulgada el 23 de agosto de 1996, Ley de Interpretación Auténtica del Artículo 112 de la Constitución (CIDH, 1999). Asimismo, con relación al referéndum para aprobar o no con voto popular la re-reelección del presidente, posibilidad que fue rechazada por la mayoría fujimorista de Cambio 90-Nueva Mayoría y sus aliados en el Congreso.

23 Tratando de explicar la "decepción" que aparejó la gestión presidencial de Alejandro Toledo en su cuarto año de gobierno, Tanaka diagnosticó: "[...] estaríamos no solo ante la crisis de un gobierno, sino ante una profunda crisis de legitimidad del conjunto de las instituciones del régimen político" (2005: 12). 


\section{Bibliografía}

ALCALDE, J. (2004). Los Estados fallidos: La influencia del desarrollo. Lima: Centro de Estudios para el Desarrollo y la Participación (CEDEP).

BORJA, R. (2003). Enciclopedia de la política. Quito: Fondo de Cultura Económica (FCE), 3ra. ed.

CIDH. Corte Interamericana de Derechos Humanos. (1999). "Caso del Tribunal Constitucional. Sentencia de 24 de Septiembre de 1999". www.tc.gob.pe/corte_interamericana/ seriec_55_esp.pdf

COTLER, J. (1969). "Actuales pautas de cambio en la sociedad rural del Perú". En J. Matos Mar, Dominación y cambios en el Perú rural (pp. 60-79). Lima: IEP. http://archivo.iep.pe/textos/ DDT/dominacionycambioenelperurural.pdf

COTLER, J. (2000). “La gobernabilidad en el Perú: entre el autoritarismo y la democracia”. En J. Cotler \& R. Grompone, El fujimorismo: ascenso y caída de un régimen autoritario (págs. 13-75). Lima: IEP.

Crabtree, J. (2005). Alan García en el poder. Perú 1985-1990. Lima: Peisa.

De Althaus, J. (2007). La revolución capitalista en el Perú. Lima: FCE.

De Sousa Santos, B. (2003). Globalización y Democracia. Foro Social Mundial Temático. Cartagena. www.ces.uc.pt/bss/documentos/cartagena.pdf

DEGREGORI, C. I. (2001). La década de la antipolítica. Auge y huida de Alberto Fujimoriy Vladimiro Montesinos. Lima: IEP.

ECheVerRía, J. (2006). "La democracia difícil: neopopulismo y antipolítica en Ecuador". ÍCONOS(27), 27-35. www.flacsoandes.org/iconos/images/pdfs/lconos27/i27_democracia_julioecheverria.pdf

ECHEVERRía, J. (2015). La democracia sometida. El Ecuador de la Revolución Ciudadana. Quito: Diagonal Ediciones.

FAIR, H. (agosto-octubre de 2012). "El discurso político de la antipolítica". Razón y Palabra (80). www.razonypalabra.org.mx/N/N80/V80/22_Fair_V80.pdf

GROMPONE, R. (2005). La escisión inevitable. Partidos y movimientos en el Perú actual. Lima: IEP. LEVITSKY, S., \& CAMERON, M. (2003). “Democracy Without Parties? Political Parties and Regime Change in Fujimori's Peru". Latin American Politics and Society, 45(3).

LYNCH, N. (1999). Una tragedia sin héroes. La derrota de los partidos y el origen de los independientes. Perú, 1980-1992. Lima: Fondo Editorial de la Universidad Nacional Mayor de San Marcos. www.nicolaslynch.com/sites/default/files/libros/Libro\%201999\%20 Una\%20tragedia\%20sin\%20heroes.pdf

LYNCH, N. (2000). Política y antipolítica en el Perú. Lima: Desco. 
MAYORGA, R. (1995). “Antipolítica y neopopulismo en América Latina: análisis comparativo del Perú, Brasil y Bolivia". En R. Mayorga, Antipolítica y neopopulismo (pp. 7-81). La Paz: Centro Boliviano de Estudios Multidisciplinarios (CEBEM).

O’DonNELL, G. (1994). “Democracia delegativa”. Journal of Democracy en Español, 9-23. www. journalofdemocracyenespanol.cl/pdf/odonnell.pdf

O’DonnelL, G. (2010). Revisando la democracia delegativa. Casa del Tiempo, III(31), 2-8. www.uam.mx/difusion/casadeltiempo/31_iv_may_2010/casa_del_tiempo_elV_ num31_02_08.pdf

QUIJANO, A. (1977). "Polo marginal y mano de obra marginal en la economía latinoamericana". En A. Quijano, Imperialismo y "marginalidad" en América Latina (pp. 239-287). Lima: Mosca Azul Editores.

RoItMAn, M. (2004). El pensamiento sistémico. Los orígenes del social-conformismo. México, D.F.: Siglo XXI-CIICH-UNAM.

Romero, A. (2012). Miserias de la Economía. El fetichismo de la ciencia económica. Lima: Editorial Horizonte.

TANAKA, M. (1998). Los espejismos de la democracia. El colapso de los partidos políticos en el Perú, 1980-1995, en perspectiva comparada. Lima: IEP.

TANAKA, M. (2005). Democracia sin partidos. Perú, 2000-2005. Los problemas de representación y las propuestas de reforma política. Lima: IEP.

TOURAINE, A. (1998). ¿Qué es la democracia? México: FCE. 